\title{
Mitral Valve Vena Contracta Width
}

National Cancer Institute

\section{Source}

National Cancer Institute. Mitral Valve Vena Contracta Width. NCI Thesaurus. Code C127582.

The width of the vena contracta of the mitral valve. 